\title{
Distribution levels of lead and cadmium within various fresh meat tissues of beef, goat and lamb and their consumption risk assessment
}

\author{
P. J. Obeid, M. Younis, C. Saliba \& J. El-Nakat \\ Department of Chemistry, University of Balamand, Lebanon
}

\begin{abstract}
Meat is widely considered to be a good source of protein, vitamins and minerals such as iron, selenium, zinc, vitamin B. Besides consuming meat muscle tissues, it is well known that in the Mediterranean area certain populations also consume other meat tissues as the bone marrow, fats, and what is known as "Fashi" or "Ma'alak" which contains the kidneys, spleen, liver, heart, and lungs. In addition, muscle, liver and kidney tissues of such organisms are widely consumed raw, without any further processing. The risk arises from the fact that such meat products are obtained from organisms which in turn have accumulated toxic metals in their tissues. Therefore, levels of lead $(\mathrm{Pb})$ and cadmium $(\mathrm{Cd})$ from various fresh meat tissues of beef, goat and lamb have been determined in Lebanon for the first time. Their inter- and intra-levels distribution were assessed and compared. Their potential exposure risk from dietary intake was also studied. A total of two hundred and forty $(\mathrm{n}=240)$ samples of fresh meat tissues ( 80 beef, 80 goat and $80 \mathrm{lamb}$ ) were collected over a period of several months from various slaughter houses. From each type of organism, five samples of nclusion tissues (heart, liver, fat, muscle, lung, kidney, bone marrow and spleen) were taken. Each individual sample was then subdivided into subsamples for subsequent analysis and quality control purposes. High-pressure closed vessel acid-assisted microwave digestion was used to digest all samples while graphite furnace atomic absorption spectroscopy was used for the quantification of the toxic metals. The data showed that the mean levels of $\mathrm{Pb}$ in goats ranged from 2.66 to $69.84 \mu \mathrm{g} / \mathrm{Kg}$ for the various tissues studied. In beef, they ranged from 0.50 to $41.34 \mu \mathrm{g} / \mathrm{Kg}$. While in lamb, levels ranged from 1.59 to $95.95 \mu \mathrm{g} / \mathrm{Kg}$. Meanwhile, the levels for $\mathrm{Cd}$ ranged from 2.39 to $635.86 \mu \mathrm{g} / \mathrm{Kg}$ for goat, 0.55 to $173.72 \mu \mathrm{g} / \mathrm{Kg}$ for beef, and 1.37 to $688.95 \mu \mathrm{g} / \mathrm{Kg}$ for lamb. Based on the inter-
\end{abstract}


level distribution of $\mathrm{Pb}$ and $\mathrm{Cd}$ in various tissues, beef meat tissues were found to have lower levels than lamb or goats. These findings suggest that consuming beef meat tissues is much safer due to less exposure to such metals. For the intralevel distribution of $\mathrm{Pb}$ in goats, the spleen, kidney and liver were found to have the highest levels. The same pattern was also found for beef and lamb. As for cadmium, the data was clear in showing that in all three types of organisms and within each of their tissues, the liver and the kidneys accumulated noticeably high amounts as opposed to their other tissues. In comparison to the maximum allowable levels (MAL) for $\mathrm{Pb}$ and $\mathrm{Cd}$ in meat (100 and $50 \mu \mathrm{g} / \mathrm{kg}$, respectively), none of the samples have exceeded the MAL for $\mathrm{Pb}$, whereas for $\mathrm{Cd}$, the liver and kidneys from all three organisms have exceeded the MAL for $\mathrm{Cd}$. According to provisional tolerable weekly intake levels (PTWI) for $\mathrm{Pb}$, and assuming a weekly consumption of $1 \mathrm{~kg}$ of the most contaminated meat tissue (lamb liver, $95.95 \mu \mathrm{g} / \mathrm{kg}$ ) by a $60 \mathrm{~kg}$ individual, $6.4 \%$ of the PTWI will be reached. For a 14year old child however, $27.4 \%$ of the PTWI will be reached suggesting that in the case of $\mathrm{Pb}$, no major health concerns are present. For cadmium however, and considering the most contaminated tissue (lamb kidney, $688.95 \mu \mathrm{g} / \mathrm{kg}$ ) 164\% of Cd's PTWI will be reached by a $60 \mathrm{~kg}$ individual. The matter is much worse for a 14 -year old child where $703 \%$ of the PTWI will be reached. In general, the work shows that beef meat tissues are safer for consumption but nevertheless, tissues from liver and kidneys of goat, beef and lamb should be minimized in all cases especially for children.

Keywords: distribution levels, lead, cadmium, meat, cow, goat, lamb, microwave acid-assisted digestion, graphite furnace atomic absorption spectroscopy (GFAAS).

\section{Introduction}

Meat is considered an important part of the food we consume and is mainly composed of essential nutrients, proteins, fats, and a good source of vitamins, phosphorous, zinc and iron [1-3]. Formation, growth and repair of tissues highly depend on certain amino acids which can only be obtained through the intake of animal proteins [4]. Being the most common sources of meat in the area of study; Beef, goats and lamb as well as their by-products such as offal, are greatly and regularly consumed. Certain meat tissues such as muscle, liver and kidney of the organisms mentioned are widely consumed raw without any further processing and are considered a delicacy. Unfortunately, Environmental pollution is on the rise with many threats to animals and humans $[5,6]$ where the high rate of industrialization can be held responsible in the widespread of many toxic elements such as lead $(\mathrm{Pb})$ and cadmium $(\mathrm{Cd})$ [7] that are largely air-borne and could be deposited by dust into the soils, the water, and even the plants that ruminants graze on [4]. In addition, cows, sheep and horses have been used as excellent indicators of pollution on vegetation due to their indiscriminate eating habits especially in starvation periods [4]. Contamination with toxic metals is considered a critical health hazard due to their toxicity, bioaccumulation and magnification in the food chain [3]. Amongst all heavy metals, $\mathrm{Pb}$ and $\mathrm{Cd}$ are 
known to be highly toxic $[8,9]$. High degree exposure to $\mathrm{Pb}$ may affect the neurological, renal, reproductive and the haematological systems with higher vulnerability in children as opposed to adults. Meanwhile, $\mathrm{Cd}$ is known to primarily affect the kidneys as well as bone demineralization [3].

In Lebanon, various meat tissues from beef, goat or lamb are widely consumed and in various manners. Besides boiling, frying or barbequing, raw liver, muscle, and kidney tissues are considered to be a delicacy and form a major part of the served appetizers. According to the handbook of analysis of edible animal by-products [10], such delicacies are referred to as offal and are region specific and comprise of edible and inedible animal by-products such as skin, bones, fatty tissues, and other internal organs. Since animal tissues can bioaccumulate toxic metals and are an important part in the food chain for humans, it then becomes essential to assess the levels of such toxins and their associated risk.

Based on the toxicity of $\mathrm{Pb}$ and $\mathrm{Cd}$, this study focused on the determination of their levels in various meat tissues of cow, goat and lamb. Moreover, their interand intra-relative distribution levels were assessed and compared by studying seven different types of tissues from each of the three species in order to further assess any health risks that might be associated with the consumption of such products. Furthermore, the work will provide awareness should any alarming numbers come to light. Most importantly, and in the absence of any governmental controls and legislations, such meat tissues might pose many health threats to individuals by way of regular consumption. In the past few years, the Lebanese ministry of public health (MOPH) [11] launched a monitoring program, based on laws and standards adopted from the world health and food and agriculture joint organizations (WHO/FAO) $[12,13]$ as well as the Lebanese standards institution (LIBNOR) [14] for monitoring the food sector and food safety. Since monitoring programs in Lebanon are still in their infancy stage, monitoring reports have included by far water safety in general, waste and pest control, infrastructure for food safety, processing, shipping, receiving and storage, personal hygiene, as well as food sample analysis focusing on several types of bacteria, parasites and viruses. Such reports did not include any data pertaining to any toxic heavy metals contamination and thus can be considered non-complete from safety and health risk point of view. In addition, and to our knowledge, this is the first report to determine toxic metal contamination in meat samples in our area and should be considered extremely important and informative in shedding the light on whether individuals are at risk or not, what is safe for consumption and what should be minimized.

\section{Materials and methods}

\subsection{Reagents and glassware}

Prior to any application, all plastic and glass-wares used throughout the study were washed with soap and tap water, rinsed with $\mathrm{ddH}_{2} \mathrm{O}$ (Milli-Q system (Millipore, Numelab), and then soaked overnight in 10\% nitric acid solution. 
Prior to usage, any item was washed three times with $\mathrm{ddH}_{2} \mathrm{O}$ [9]. Acid-digested samples were stored in 50-mL polypropylene conical tubes (LaboTech, Lebanon), which were soaked in $10 \%$ nitric acid solutions, and washed with $\mathrm{ddH}_{2} \mathrm{O}$ prior to use. Reagents and sample cups (Biotechno, Lebanon) were also soaked and washed thoroughly with $\mathrm{ddH}_{2} \mathrm{O}$ before their use. Working standards for lead and cadmium were prepared using standard solutions supplied by RomilPure chemistry (Standard solutions 1000ppm element reference solution). Concentrated nitric acid (65\%) and hydrogen peroxide (30\%) of high quality and purity were used for the sample digestion. Purified nitric acid was also used for the preparation of wash solution and diluents for the Graphite Furnace Atomic Absorption Spectrometer (GFAAS) [9]. Ascorbic acid 99.99\% pure and trace metal basis (purchased from Sigma-Aldrich) was used as pure chemical matrix modifier for lead detection, while magnesium nitrate $99.99 \%$ pure and trace metal basis (purchased from Sigma-Aldrich) was used as pure chemical matrix modifier for cadmium detection, in the GFAAS. Certified Reference Material (CRM) (SRM1577C Bovine Liver NIST National Institute of Standards and Technology) was used to validate all analytical procedures used.

\subsection{Samples and sample treatment}

Fresh meat samples (100-200g each) of various tissues (muscle, heart, lung, kidney, liver, fat, bone marrow, and spleen) were purchased from different abattoirs in North Lebanon. The eight types of tissues were collected from the same organism (beef, goat, lamb) after slaughter and the process was repeated from other organisms and from different places. A total of 240 samples of beef, goat, and lamb were collected. For each organism, the eight different tissues were collected twice from each one organism, were labeled correctly and stored in acid pre-cleaned $50-\mathrm{mL}$ conical tubes at $-20^{\circ} \mathrm{C}$ until treatment.

For each collected sample, about $50 \mathrm{~g}$ were taken and cut into very small pieces by using pre-cleaned stainless steel knives and tweezers. They were then dried in a programmable oven (Venticell, W.P. Katul) at $70^{\circ} \mathrm{C}$ overnight until a constant sample weight was obtained. After drying, $0.5 \mathrm{~g}$ of each sample was weighed and transferred to a Teflon reaction vessel specific for the Ethos 1 microwave digestion oven (Milestone Ethos 1 Labstation) followed by the addition of $7 \mathrm{~mL}$ of purified concentrated nitric acid $(65 \%)$, and $1 \mathrm{~mL}$ of $30 \%$ concentrated hydrogen peroxide. Similarly, and for quality control purposes, $0.5 \mathrm{~g}$ of the certified reference material (CRM) was also included in each batch and treated in the same manner as any other sample. After addition of the acid, the vessels were left under a fume extraction hood for at least 15 minutes to allow the formed gases to escape. The vessels were then sealed and placed inside the microwave oven and digested using a three-step program. During the first step, samples were heated from room temperature to $200^{\circ} \mathrm{C}$ in $30 \mathrm{~min}$ at 1000 watts. The second step consisted of maintaining the samples at $200^{\circ} \mathrm{C}$ for $30 \mathrm{~min}$ at 1000 watts. In the final step, samples were brought to room temperature. Digested samples $(\sim 7 \mathrm{ml})$ were transferred into $25 \mathrm{~mL}$ volumetric flasks and were diluted with $\mathrm{ddH}_{2} \mathrm{O}$ up to the mark prior to their transfer to $50 \mathrm{~mL}$ 
polypropylene tubes in which they were stored in the refrigerator until analysis time by GFAAS.

For trace metal analysis, a Thermo-Electron $M$ series graphite furnace atomic absorption spectrometer (GFAAS) equipped with deuterium and Zeeman background correction (Zeeman Furnace GF95Z) together with an Autosampler (FS95) was used. The sample atomization was carried out in specialized graphite tubes (Thermo Elemental Omega Platform Extended Lifetime Cuvettes). Coded hallow cathode lamps of lead and cadmium (Thermo-electron Corporation, Germany) were included in the GFAAS's carousel, where the lamp selection was done automatically based on the metal to be analyzed $[9,15,16]$. During all stages of $\mathrm{Pb}$ and $\mathrm{Cd}$ analysis, 99.999\% pure argon gas (supplied by Chehab Industrial and Medical Gases S.A.L., Lebanon) was used as an internal inert gas with a flow of $300 \mathrm{~mL} / \mathrm{min}$.

\subsection{Sample analysis by GFAAS}

The optimized parameters for $\mathrm{Pb}$ and $\mathrm{Cd}$ were entered into the software of the GFAAS. Mother solutions (10 ppb for $\mathrm{Pb}$ and $1 \mathrm{ppb}$ for $\mathrm{Cd}$ ) for the calibration curve were simultaneously prepared by dilution of $1000 \mathrm{ppm}$ stock solutions by using 10 fold dilutions each time, so as to diminish the analytical preparation errors as much as possible. The mother solutions were used by the GFAAS's auto-sampler in order to create automatically a specified five-point calibration curve specific for each metal. All dilutions were done using $0.5 \%$ nitric acid solution. A $0.1 \%$ nitric acid solution was used to wash the auto-sampler injection tube between each dilution so as to prevent any cross-over contamination between the calibration points and the samples $[9,15,16]$.

Aliquots of approximately $1 \mathrm{~mL}$ of each digested sample as well as digested CRMs were placed in a 1-mL polypropylene sample cups and were arranged into the auto-sampler according to an auto-sampler guide generated automatically by the software. Standard mother solution, diluents, as well as the matrix modifiers were placed in $20 \mathrm{~mL}$ polypropylene reagent cups, and loaded into the autosampler according to the same auto-sampler guide $[9,15,16]$.

The total analysis, starting from calibration curve preparation ending up with the sample analysis was programmed to be carried out without any human interference thus decreasing contamination sources $[9,15,16]$. With the purpose of eliminating any possible contamination, the auto-sampler washes itself after each run with $0.1 \%$ nitric acid solution.

The auto-sampler can perform up to sixty samples injections in addition to all the necessary dilutions and preparations, in one run, thus ensuring high quality control of analysis. On the other hand, all specimens were run in batches with digested blanks and digested CRMs. Digestion blanks were used to test for the presence of any possible contamination throughout the whole procedure $[9,16]$. Furthermore, all samples were analysed in triplicates, where a mean value was calculated. For further quality control, the instrument was programmed to periodically re-measure sample blanks and standards from the calibration curve every 10 samples to check for any instrumental variations during the analysis, thus ensuring fidelity and consistency of the data. Moreover, and for 
investigating the recovery of the whole procedure, every batch included a sample of certified reference material so as to ensure that the method used was accurate and that the produced results are genuine. In this case, all our CRM samples had recovery values that ranged within the acceptable analytical range of 80-120\%.

\section{Results and discussion}

The distribution levels of lead and cadmium within various fresh meat tissues of beef, goat and lamb have been determined. The data is presented in Table 1 .

Since such studies have not been carried out before in our area, it becomes crucial to do this work and become aware of whether or not individuals are at risk from consuming such tissues.

Table 1: Lead and cadmium mean concentrations $(\mu \mathrm{g} / \mathrm{kg})$ in organs of different animals.

\begin{tabular}{|l|c|c|c|c|c|c|}
\hline & \multicolumn{2}{|c|}{ Beef } & \multicolumn{2}{c|}{ Goat } & \multicolumn{2}{c|}{ Lamb } \\
\hline & Pb & $\mathbf{C d}$ & Pb & Cd & Pb & Cd \\
\hline Muscle & 0.62 & 2.57 & 3.99 & 3.82 & 1.59 & 3.69 \\
\hline Heart & 5.41 & 64.42 & 2.66 & 6.31 & 3.67 & 6.48 \\
\hline Fat & 6.74 & 0.55 & 16.79 & 2.39 & 7.75 & 1.42 \\
\hline Bone marrow & 26.12 & 0.73 & 3.27 & 2.72 & 22.18 & 1.37 \\
\hline Lung & 0.50 & 4.88 & 6.31 & 17.85 & 3.94 & 8.93 \\
\hline Spleen & 3.00 & 6.40 & 29.66 & 11.64 & 23.22 & 14.60 \\
\hline Kidney & 6.05 & 173.72 & 33.90 & 635.86 & 28.82 & 688.95 \\
\hline Liver & 41.34 & 57.58 & 69.84 & 133.83 & 95.95 & 99.02 \\
\hline
\end{tabular}

As the work focused on the distribution levels of lead and cadmium in various meat tissues from different organisms and their possible consumption risk, the data may be looked at from different aspects in order to assess the levels of such metals and their potential risk. First, the data clearly reveals that $\mathrm{Pb}$ and $\mathrm{Cd}$ were detected in all samples, thus suggesting that the two toxic metals are widely spread in our environment. Considering the inter-level distribution of $\mathrm{Pb}$ and $\mathrm{Cd}$ in various tissues, beef meat tissues in general showed the lowest concentrations of both metals in comparison to goat and lamb (Table 1). This suggests that the consumption of beef tissues should generally provide less exposure to either metals as opposed to goat and lamb. This might be due to several factors such as the size of the animal, the distribution characteristics of the metal within the organism as well as the feeding habits in which the animal was brought up in. In considering perhaps the most important factor which is the feeding habit, in Lebanon, cows are generally raised indoors, whereas goat and lamb are raised on pasture. Similarly, Oskarsson et al. [17] have reported similar observations where Pd levels in cows (muscle) raised on pasture were higher than those raised indoors [17].

Considering the MAL for $\mathrm{Pb}(100 \mu \mathrm{g} / \mathrm{kg})$ in the EU directive 466/2001 [18], none of the analyzed samples have exceeded this level (Figures 1, 2, and 3). 
Nonetheless, the liver of lamb came as close as $96 \%$ from the MAL of lead (Figure 3). Since the data reports mean concentrations of resamples for both metals, a closer look at the individual samples (raw data) prior to taking the mean, reveals that $20 \%$ goat liver, and $40 \%$ of lamb liver samples have exceeded the MAL of $\mathrm{Pb}$, whereas none of the samples in cow have done so. This again, suggests that consumption of beef tissues may be less of a health hazard as

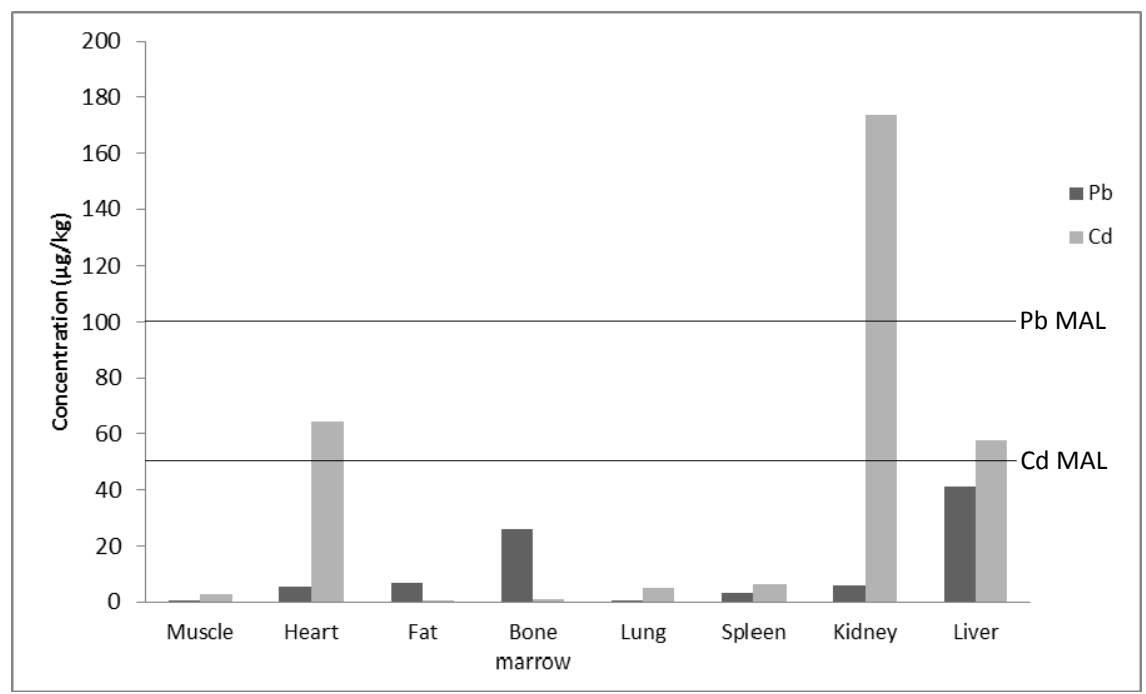

Figure 1: Lead and cadmium concentrations in different tissues of beef.

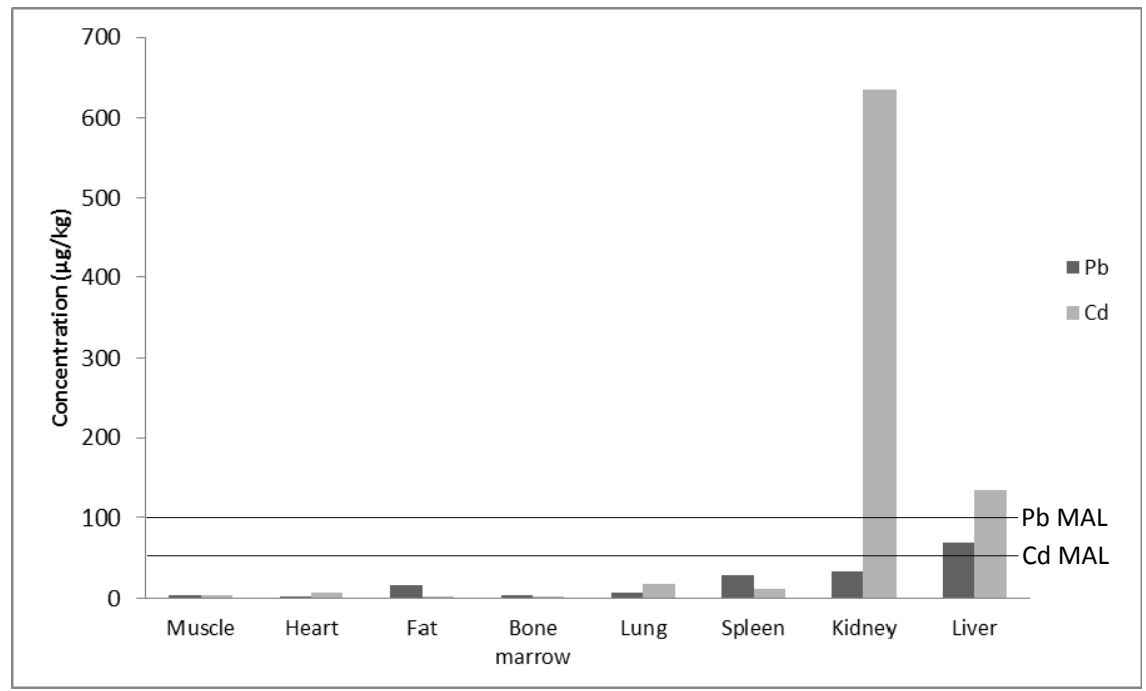

Figure 2: Lead and cadmium concentrations in different tissues of goat. 
opposed to consuming tissues from goat or lamb. On the other hand, and in comparison of the mean values of Cd obtained with the MAL of Cd $(50 \mu \mathrm{g} / \mathrm{kg})$ [18], cow heart tissues, as well as liver and kidney tissues of all three organisms studied have exceeded the MAL of Cd. Similarly, and by extracting sample information from the raw data for $\mathrm{Cd}$ prior to mean calculations, $80 \%$ of liver and kidney sample tissues in goat have exceeded the MAL of Cd, while $20 \%$ heart, $40 \%$ liver and kidney of cows, and $70 \%$ of liver, $90 \%$ of kidney of lamb, have all exceeded the Cd MAL. The results obtained are very similar to data reported elsewhere [19].

According to several studies extending from year 1995 to 2014 [3, 20, 21], the high accumulation of such metals in the liver and kidney was found to be directly related to their function as storage and excretory organ, respectively. In addition, going back to the fact that cows are raised indoors while goats and lamb are raised on pastures strongly suggests that goats and lambs are more vulnerable to higher exposures to such toxic metals since there are no limits on what they feed on. Such unidentified sources of toxic metals could very well be attributed to high accumulation of metals from the environment onto plants, municipal wastes, lead and nickel-cadmium batteries which are non-responsibly discarded, electronic wastes, all of which are dumped and burnt in our area. Considering the intra-level distribution of $\mathrm{Pb}$ and $\mathrm{Cd}$ in the various tissues studied, liver and kidney tissues of all organisms studied showed the highest amounts of bioaccumulation as opposed to all other tissues within each organism (Figures 1, 2, and 3). This data strongly suggests that consumption of liver and kidney tissues from any of the three organisms may present a health risk if included regularly in the diet.

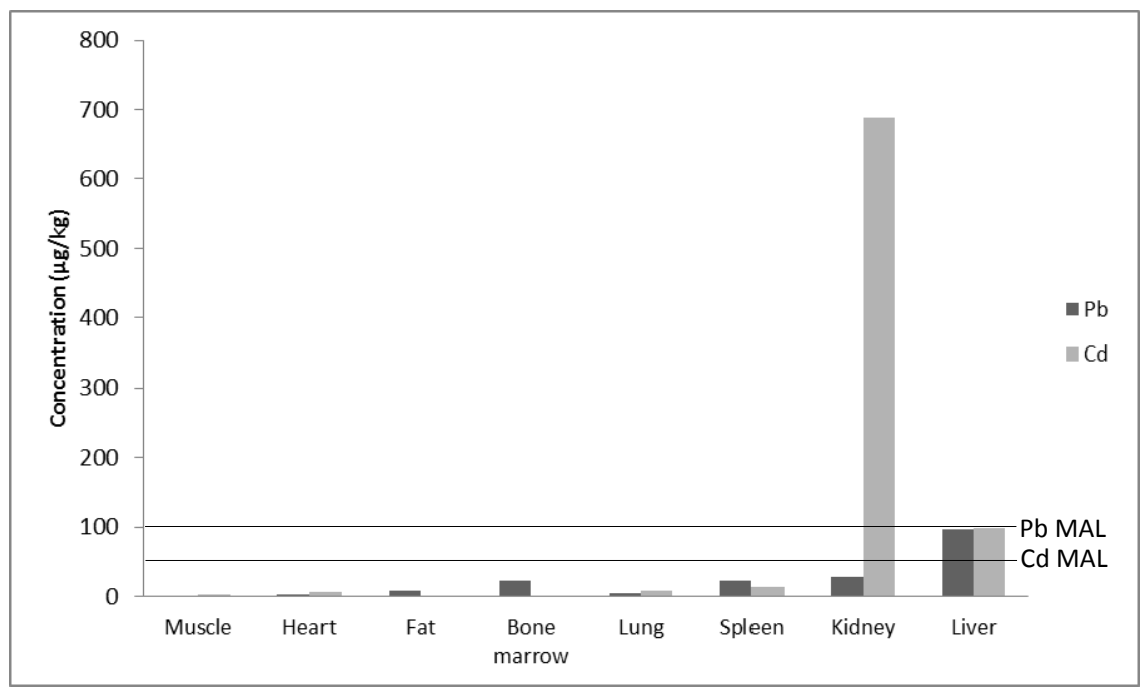

Figure 3: Lead and cadmium concentrations in different tissues of lamb. 
According to provisional tolerable weekly intake levels (PTWI) for $\mathrm{Pb}$ [9], and assuming a weekly consumption of $1 \mathrm{~kg}$ of the most contaminated meat tissue (lamb liver, $95.95 \mu \mathrm{g} / \mathrm{kg}$, Table 1) by a $60 \mathrm{~kg}$ individual, $6.4 \%$ of the PTWI will be reached. For a 14-year old child however, $27.4 \%$ of the PTWI will be reached suggesting that in the case of $\mathrm{Pb}$, no major health concerns are present. For cadmium however, and considering the most contaminated tissue (lamb kidney, $688.95 \mu \mathrm{g} / \mathrm{kg}$, Table 1) $164 \%$ of Cd's PTWI will be reached by a $60 \mathrm{~kg}$ individual. The matter is much worse for a 14 -year old child where $703 \%$ of the PTWI will be reached. This suggests once again that beef meat tissues are safer for consumption but nevertheless, tissues from liver and kidneys of goat, beef and lamb should be minimized in all cases especially for children.

\section{Conclusion}

The presence of $\mathrm{Pd}$ and $\mathrm{Cd}$ in various meat tissue samples from cow, goat and lamb were analysed and determined. Since both metals have been detected in all samples, this will raise serious concerns on the extent of pollution in our environment. Based on the inter-level distribution of both $\mathrm{Pd}$ and $\mathrm{Cd}$ in the tissues of cow, goat and lamb, beef tissues were found to contain lower levels of the metals in question, suggesting that beef in general may be considered safer for consumption as opposed to goat and lamb. Based on the intra-level assessment of both metals, the liver and kidney tissues were found to contain high levels of both metals to a point where their MALs have been far exceeded. Regarding health risks from consuming such products, it is advisable that consumption of goat and lamb should be minimized as opposed to beef. The study also strongly suggests that consumption of liver and kidney tissues from any type of organism should be highly minimized since such organs were found to accumulate the highest amounts of $\mathrm{Pb}$ and $\mathrm{Cd}$.

In light of this, researchers in the area as well as national health organizations should really engage in constant monitoring and evaluation of levels toxic metals in the environment and in foodstuffs so as to shed some light on the extent of contamination and its sources and perhaps may be able to take measures in controlling such levels in the future.

\section{References}

[1] Akan, J. C., Abdulrahman, F. I., Sodipo, O. A., \& Chiroma, Y. A., Distribution of heavy metals in the liver, kidney and meat of beef, mutton, caprine and chicken from Kasuwan Shanu Market in Maiduguri Metropolis, Borno State, Nigeria. Research Journal of Applied Sciences, Engineering and Technology, 2(8), pp. 743-748, 2010.

[2] Williams, P., Nutritional composition of red meat. Nutrition \& Dietetics, 64(s4), S113-S119, 2007.

[3] Nkansah, M. A., \& Ansah, J. K., Determination of Cd, Hg, As, Cr and Pb levels in meat from the Kumasi Central Abattoir. International Journal of Scientific and Research Publications, 4(8), pp. 1-4, 2014. 
[4] Bala, A., Muhammad, L. U., Pewan, S. B., Ahmed, M. S., Muhammad, M., Junaidu, A. U., ... \& Anzaku, S. A., Determination of lead (Pb) residue in kidney, liver and muscle of slaughtered cattle in Jos Central Abattoir, Plateau State, Nigeria. J. of Environ. Sci. Toxicology and Food Technology (ISOR-JESTFT), 7(6), pp. 48-51, 2013.

[5] Ihedioha, J. N., \& Okoye, C. O. B., Dietary intake and health risk assessment of lead and cadmium via consumption of cow meat for an urban population in Enugu State, Nigeria. Ecotoxicology and environmental safety, 93, pp. 101-106, 2013.

[6] Yabe, J., Nakayama, S. M., Ikenaka, Y., Muzandu, K., Ishizuka, M., \& Umemura, T., Uptake of lead, cadmium, and other metals in the liver and kidneys of cattle near a lead-zinc mine in Kabwe, Zambia. Environmental Toxicology and Chemistry, 30(8), 1892-1897, 2011.

[7] Okorafor, K. A., \& Amadiali, P., Concentrations of some metals in kidneys and liver of goats slaughtered at Atakpa Abattoir, Calabar South, Cross Rivers State, Nigeria. Biosciences Research in Today's World, 1(1), pp. 90-96, 2015.

[8] Binkowski, L. J., Is the meat of wild waterfowl fit for human consumption? Preliminary results of cadmium and lead concentration in pectoral muscles of Mallards and Coots shot in 2006 in southern Poland. The Journal of Microbiology, Biotechnology and Food Sciences, 1, 1120, 2012.

[9] Obeid, P.J. et al., Determination of levels of lead and cadmium contamination in meat products sold in northern Lebanese markets. Int. J. of Safety and Security Eng., 4(4), pp. 329-344, 2014.

[10] Nollet, Leo ML, and Fidel Toldrá, eds. Handbook of analysis of edible animal by-products. CRC Press, 2011.

[11] MOPH (Lebanese Ministry of Public Health), 2010. http://www.moph.gov.lb/Prevention/Pages/FoodSafetyRegulations.aspx

[12] Understanding the Codex Alimentarius, Third edition, Rome, 2006. ftp://ftp.fao.org/codex/Publications/understanding/Understanding_EN.pdf

[13] Food safety, Fact sheet $\mathrm{N}^{\circ} 399$, December 2015. http://www.who.int/ mediacentre/factsheets/fs399/en/

[14] LIBNOR, Lebanese Standards Institution Co-creating Responsibility. http://www.libnor.gov.lb/ViewCatalogs.aspx?language=en

[15] Al-Chaarani, N., Measurement of levels of heavy metal contamination in vegetables grown and sold in selected areas in Lebanon. Jordan Journal of Chemistry, 4(3), pp. 305-317, 2009.

[16] Obeid, P.J. et al., Determination and assessment of total mercury levels in local, frozen and canned fish in Lebanon. Journal of Environmental Sciences, 23(9), pp. 1-6, 2011.

[17] Oskarsson, Agneta, Lars Jorhem, Johanna Sundberg, Nils-Gunnar Nilsson, and Lennart Albanus. "Lead poisoning in cattle - transfer of lead to milk." Science of the Total Environment 111, no. 2-3: pp. 83-94, 1992. 
[18] Dailos, G-W., Karlsson, L., Caballero, A., et al., Lead and Cadmium in meat products consumed by a Spanish population (Tenerife Island, Spain). Journal of Food Additives and Contaminants, 23(8), pp. 757-763, 2006.

[19] Ihedioha, J. N., \& Okoye, C. O. B., Cadmium and lead levels in muscle and edible offal of cow reared in Nigeria. Bulletin of environmental contamination and toxicology, 88(3), pp. 422-427, 2012.

[20] Stoyke, M., Doberschutz, K. D., \& Lusky, K., Heavy metal contents (cadmium, lead and mercury) in selected feedstuff, organs and tissue in cattle found different sites of Brandenburg. Mengen. Spureneler. Arbeitstag, 15, pp. 269-276, 1995.

[21] Pompe-Gotal, J., \& Crnic, A. P., Cadmium in tissues of roe deer (Capreolus capreolus) in Croatia. Veterinarski arhiv, 72(6), pp. 303-310, 2002. 